\title{
Importance of Adopting a Drought Policy
}

\author{
Abdullahi Hassan Gana \\ Department of Biological Sciences \\ Yobe State University, Damaturu-Nigeria
}

\section{Doi:10.5901/ajis.2013.v2n12p69}

\begin{abstract}
This research aims at exploring the importance of Drought Policy at International, National and Local level. Water, its importance and effects of its scarcity were discussed. The impact of climate change on drought in the $21^{\text {st }}$ century is intense as this disaster is frequently reoccurring in many regions around the world regardless of the climatic conditions and geographic location. Australia is the only country that has adopted a Drought Policy in the world. Georgia State in the United State also has a Drought Policy in place. The Drought Policies were briefly reviewed to show the importance of adopting such policy. The policy provides safety net to affected victims.
\end{abstract}

Keywords: drought, water, policy, disaster, hazard

\section{Introduction}

Water is a chemical substance which contains a molecule of oxygen and two atoms of hydrogen $\mathrm{H}_{2} \mathrm{O}$ which are connected by covalent bonds (Gosling et al., 2010). Water is a resource that exists in dynamic forms which are solid, liquid and gas (National Atlas, 2011). Availability of water is one of the serious problems in the world of mankind today (Hamdy et al., 2003). Water covers more than $70.9 \%$ of the earth surface, and it is also important to all forms of life (National Atlas, 2011). On the earth's surface oceans account for $96.5 \%$ of the total water; $1.7 \%$ ground water and glacier, fresh water accounts for only $0.003 \%$. Water on earth circulates continuously through what is known as the hydrologic cycle (National Atlas, 2011).

\section{Methodology}

During the research previous literature on the socioeconomic effects of drought were reviewed using library catalogue, journals, books and published conferences.

\section{The Importance of Water}

Water is a vital resource making it very important in the part of every living thing on the planet (Molden, 2007). It is used for various reasons which include:

- Drinking, all living organism need water for their survival. In case of human being approximately $60 \%$ of the body is water, and $95 \%$ of that is blood. On average, a human body needs 2 litres per day to make it function normally (Molden, 2007)

- Agricultural it is used to grow farm produce for human consumption and grazing animals. However, other living organisms, both plants and animals, need water for their survival. In many countries of the world, water is used for irrigation and a significant proportion of the population may rely on agriculture as their primary source of income, as this sector consumes highest percentage of water in the world every year (Molden, 2007).

- Domestic use - water is used every day in houses for things such as cooking, washing, 
bathing, and cleaning (Leon, 2012)

- Industrial, water is been used by industries for their daily activities, of which it is believed that this sector consumes a lot during manufacturing processes. The industrial consumption of water increases its demand in many developed countries and some fast growing economies in the world. Although not only developed or developing countries are in serious demand of water but many countries around the world are now facing the same problem (Molden, 2007).

\section{The Effect of Water Scarcity}

There is much talk about the issue of water crisis around the world. It is believed that more than 1.2 billion people globally lack access to safe and clean water for their daily activities (Rijsberman, 2006). Many have suggested that if there was a third World War it would be as a result of water security. More than 900 million people in rural areas live in poverty; they are surviving on less than a dollar per-day which is also in line with lack of access to water for their livelihoods (WHO, 2003). Rijsberman (2006) defined water scarcity as lack of access to safe and affordable water to satisfy the daily needs of individuals. The term 'water scarcity' is also referred to as water insecurity. The increasing demand on water is directly related to issues such as population growth, economic progress, land use change, climate change and water pollution. These are combined to make its availability a serious environmental issue in the future (Davies and Simonovic, 2003). The problems associated with lack of sufficient water have affected the lives of millions of people around the world. Adverse impact of water shortage can affect man mentally, socially and economically. The modern global awareness of water scarcity has increased the interests of many governmental and non-governmental organisations toward the modelling of water resource management both in terms of demand and supply of water (Davies and Simonovic, 2003).

It is also believed that in the next 50 years problems related to scarcity of water and pollution of water bodies could virtually affect one third of the world's population (Hamdy et al., 2003). Water scarcity is a situation that affects the normal supply of water or its quality which renders it insufficient to satisfy the demand from all sectors, such as environment, agriculture, industrial and domestic (Gosling et al., 2011). On a global scale more than half of the world's population now live in urban areas, and this is expected to rise by $60 \%$ by 2030 (Nyemba et al., 2010). The problem of water scarcity is worse in the regions with high temperature and less humidity, which is mostly attributed to poor rainfall (Nyemba et al., 2010).

The problems of water affect not only the human population but the ecosystem services. Water has significant impacts on all social, economic and environmental sectors which in turn threatens the sustainability of natural resources (UN water, 2007). This is reflected in the fact that individuals, governments and companies can secure water for their operations and daily activities without considering the consequences on the natural environment (UN water, 2007). Lack of access to safe water has impacts on the well-being of people. Improper sanitization and poor personal hygiene causes significant health issues particularly diseases such as diarrhoea, cholera, typhoid and malaria claiming more than 2.18 million lives every year of which one third are children under the age of 5 (Pru"ss et al, 2002; UN water, 2007 ).

Understanding the context of water scarcity has significant impacts on agricultural and industrial activities. A 2006 report discussed the issues of high profile water shortage in Australia, Botswana, Canada, China, Fiji, Kuwait, Liberia, Malawi, Pakistan, Philippines, South Africa, Uganda, United Arab Emirates and United States of America. According to the UN (2007) some experts are divided on the issue of whether the world is seriously facing the problem of water shortages. Rijsberman (2006) argued that water is truly scarce in the physical sense (as a supply) and is available but the method of using the resource is the problem (a demand problem). However, it was concluded that water is indeed physically scarce (Pru"ss et al, 2002). Addressing the issue of water scarcity needs a holistic, inter-sectorial and multidisciplinary approach with management that 
can guarantee proper usage of resources for the equitability of social and economic welfare without compromising the ecosystem (UN water, 2007; Gosling et al., 2011). According to El Kharraz et al., (2012) making a proper water management plan is a key stepping stone in reducing poverty and increasing economic growth.

\section{Drought as a Natural Hazard}

Several authors and scholars have identified drought as a natural hazard. Considering that droughts have various impacts in different parts of the world. It is also identified as one of the major global threat of the $21^{\text {st }}$ century. Drought is considered a natural hazard as it occurs naturally and its severe form has negative impacts on people and their immediate environment; with the growing demand on water aggravating its threats (Mishra and Singh, 2011). The occurrence of drought is complex and also depends on the hydrological processes that feed moisture to the atmosphere. When a dry hydrological condition occurs it initiates a positive feedback mechanism, with moisture depleting from the top-soil reducing the rates of evapotranspiration, and in turn decreasing the atmospheric relative humidity (Bravar and Kavvas, 1991). The lower the relative humidity the lower the probability of rainfall, as it rarely reaches saturation point at low-pressure system. Disturbance from oceans and seas brings enough moisture from outside the dry region and can provide sufficient rainfall to reduce drought conditions in an area (Bravar and Kavvas, 1991). Drought is also ranked first amongst other natural hazards in terms of numbers of affected people (Wilhite, 2000b). However, drought differs from other natural hazards in different ways (Wilhite, 2000a). According to Wilhite (2000a) there are four main factors that differentiate drought from other natural hazards, which includes the following:

- It is difficult to determine when a drought event starts and ends and whether the impacts increases and accumulate slowly over a considerable period of time

- There is no universal definition for drought making it difficult to diagnose drought or defining the boundaries.

- The impacts do not affect structures (buildings and homes) and spreads over a large geographic area. Other natural hazards such as hurricanes, floods, tornadoes, and earthquakes generate damage to structures.

- Anthropogenic or human activities can directly trigger the impacts of drought unlike other natural hazards. Factors such as over-exploitation. Over-cultivation, excessive irrigation and over-population directly affect the ability of soil to capture and hold water.

Considering the different aspects determining drought other scholars have different thoughts on how to rank and classify drought. It is ranked considering the following factors:

The degree of severity, the length of the event, total areal extent, total loss of life, total economic loss, social effect, long-term impact, suddenness, occurrence associated with other hazards.

These factors are used to rank drought as first amongst natural hazards (Bryant, 1991). Drought is considered as the fatal natural hazard determined by research conducted and its ripple socio-economic aspects of human life (Bryant, 1991).

\section{Need for Drought Policy}

Compared to other resources water is a renewable resource but when it is gone it cannot be retrieved, and has no alternatives or substitutes (SABMiller and WWF, 2009). The way water is been managed in countries around the world is unsustainable, considering that most nations have not attached any priority to sustainable water management for the future (SABMiller and WWF, 2009). There is a need for countries around the world to consider and take a step forward toward mitigating and addressing the issues of water insecurity and drought. According to the Integrated Regional Information Networks report, (IRIN 2012) a national drought policy could not only involve the establishment of institutions for effective monitoring and setting up early warnings, but it would 
also empower the affected communities to demand safety nets and protection. The ultimate goal of a National Drought Policy would be to create efficient drought-resilient societies, which that would make it mandatory for countries or states to provide safety nets, such as insurance, for the victims, financial assistance and provide lost items (Garrotte et al., 2007). It is important to initiate such policies as climate change is unfolding, resulting in drought becoming more intense and frequent (IRIN, 2012).

The concern regarding lack of preparedness, mitigation and inappropriate drought management policy around the world is now a serious issue according (Sivakumar et al., 2011). Despite the frequent occurrence of drought in history, and the fact that this has had significant impacts on several socio-economic sectors and the environment, no concrete effort or dialogue has been made towards curtailing the issue. In order to address the problems of national drought policy, the World Meteorological Organisation (WMO) and United Nations Convention to Combat Desertification (UNCCD) in collaboration with other UN agencies have planned a High Level Meeting on National Drought Policy (HMNDP) which took place in Geneva March 2013. The new paradigm for drought policies focuses on risk management, rather than as previous on the crisis which contributed to societal vulnerability (Sivakumar and Wilhite, 2002).

Risk identification and early warning are the key areas identified by the Hyogo Framework of Action, which is a 10 year global policy approved in 2005 to mitigate the risk from drought related disasters (IRIN, 2012). However, it has been noticed that whenever a natural hazard, such as drought, flood, earthquake or volcanic activity occurs governments and donors only focus on response, recovery and reconstruction (termed the '3Rs') with little emphasis given to risk management to mitigate future impacts (Garrotte et al., 2007). An effective risk management strategy combines natural (hazard) and social (vulnerability) factors, which are considered during drought management (Kampragou et al., 2011). A risk management approach focuses on predisaster activities predicting hazard and vulnerability of drought for preparedness and mitigation measures. The approach is believed to increase resilience of drought in the society, if the strategies are followed (Kampragou et al., 2011). According to Alexander (2002) the key elements for predrought protection should involve the selection of indicators and relevant thresholds to characterise the type and severity of the future event, secondly, there should be risk mapping through the assessment of degree and extent of drought exposure and vulnerability, including impacts measurement in different sectors and regions, thirdly there should be a monitoring and early warning systems. It is also important to develop a drought management plan, specifying courses of action and concrete plan for responding to drought events (Alexander, 2002). Considering the current concerns with the issue of climate change, projecting and increasing the recurrence of drought intensity and duration, Australia is the only country around the world that has so far adopted drought addressing policy (Sivakumar et al., 2011). Figure 1 below is describing the management strategy of drought risk and crisis managements. Risk management which is also the strategy Australia adopted is by preparing for the disaster through prediction and early warnings. In addition, the risk management method is for protection, to mitigate future occurrence. In case of the crisis management which is for the recovery after the disaster, the impact should be assessed and then response to the incident (Stefanski, 2011). Showing the risk management structure Australia developed a National Drought Policy (NDP) (Nelson et al., 2008) in 1992 which was revised first in 1994 and again in 1997 (Sivakumar et al., 2011). 


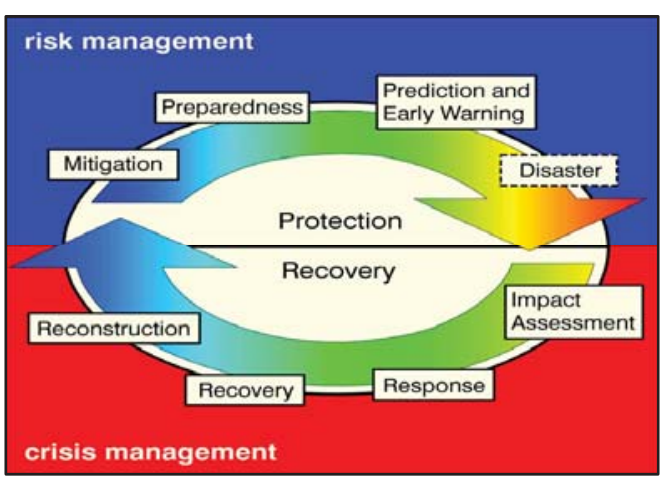

Figure 1: illustrates the process of risk and crisis management (after Stefanski, 2011).

This is based on principles of risk management (Sivakumar et al., 2011). The Australia's National Drought Policy (NDP) is based on principles of sustainable development, risk management, productivity growth and structural adjustment in the farming sector. Amongst the objectives of the policy are to encourage and help farmers in Australia to adopt self-reliant approaches to climatic variability (NDP Australia, 1997). Secondly, to protect and maintain the agricultural and environmental resources in the country and thirdly to ensure early recovery of agricultural and rural industries with long-term sustainable level (NDP Australia, 1997). Under the policy, farmers are expected to assume the responsibility for managing their risks arising from climatic variability. The Australian Government on its part is to provide a favourable working environment for property and risk management plans. The policy encourages producers to adopt property management through incentives, information transfer, education, training, land care group projects and research and development (NDP Australia, 1997). During severe events the government will provide adjustment assistance in the recovery phase and support those in financial difficulties as well. The state government is also responsible in providing subsidies or similar measures during a drought period (NDP Australia, 1997). Considering the policy provided by the government reconstruction was not given any emphasis.

Georgia, in the United States of America has also developed a Georgia Drought Management Plan (GDMP) in 2003 (GDMP, 2003). The Georgia Drought Management Plan (GDMP) focuses on long-term actions for pre-drought strategies of preparedness, mitigation; monitoring and conservation, response to short-term actions are implemented during the event according to the level of severity (GDMP, 2003). A committee was appointed to review and amend the plan after every 5 years. The plan has also identified 4 indicators which include precipitation, stream flow, reservoir level and ground water level as triggers for preparedness of drought. Agriculture, municipal and industrial water plans are also included in the plan as part of pre-drought strategies. Agricultural farmers are educated on the issues of drought and irrigation processes (GDMP, 2003). Major incentives are not stated in the management plan to encourage farmers and participants to be fully committed towards mitigating issue of drought in the state of Georgia.

The current situation of water around the globe has provoked countries such as Scotland, India, Palau, Namibia and Egypt to implement water management policies. According to Kampragou et al (2011) there is a need for the EU to initiate Drought Policy at all level. Furthermore considering the state of drought and its effects around the world, there is a need to embrace the idea of National Drought Policies. According to the literature there is a significant difference between drought policies and plans. Drought policies are rules and regulations provided by the state to address the issue, while plan is a future action created to be followed during and after the events. The HMNDP meeting has focused on the implementation of policies at national to local level. It recognises that due to funding constraints it may be difficult for poor states to adopt 
such policies without financial support.

\section{Discussion on the Need for Drought Policy}

Water is a renewable resource as when is used it cannot be retrieved and has no alternative in comparison to other resources. The issue of water across the globe showed to be a general one with almost $90 \%$ of the countries around the world facing the problem (Rijsberman, 2005). Some scholars and research institutes have mentioned that it is the inadequate management of water that causes most of the problems (SABMiller and WWF, 2009; Sivakumar et al., 2011).

Following the statement above water is a precious resource and has been misused and mismanaged in several aspects for example by households, industries and offices (Leon, 2012). If a proper policy is not in place to monitor activities, the problems of water will persist and become greater than it is at present. Water and drought managing polices will definitely help to mitigate the problems and threats. IRIN (2012) and Garrotte et al (2007) mentioned that such a step would not only involve putting policies in place but could also serve as a safety net for protection to the affected victims. Commenting, such a step would be a huge development not only to the beneficiaries but even the governments and organisations involved. Proper use and management of water would provide safe and portable water for future generations.

Considering the negligence of governments around the world, the WMO and other NGOs as mentioned above have organised a conference to investigate the issues of drought and why nations seem not to be interested in implementing National Drought Policies. Commending the effort of WMO and the organisations, this is very good achievement but this step should have been taken by governments rather than NGOs. This shows that there is lack of enough awareness amongst the governments on the adverse impact of such environmental disaster.

However, some countries have scientific research committees attached to their lawmakers, for example in the UK. The committee looks into scientific issues and enlightens the parliament about emerging problems. Considering that the UK has such a committee it is surprising that a drought policy has not been implemented, despite a Drought Act was enacted in the 1976 (Burke et al., 2010). As the problems of water shortage are engulfing the world, Nigeria is amongst the countries that have not implemented any drought policy or water management strategy. During this research efforts were made to see if Nigeria has such policy but it shows that none of these steps was taken by the country. Australia is the only country with a National Drought Policy. Australia and Georgia State in the US have adopted a drought policy as details were explained above. This is a step forward towards mitigating and addressing issues of drought. Nigeria has also not put in place any strategy or policy to deal with issues of drought.

\section{Conclusion}

Considering the literature gathered, they showed that water is a precious resource and proper utilisation of such resources is very important. Having a water management strategy or policy in place can mitigate the impact of water scarcity and increase management culture among people. Drought as mentioned in several places within the text is a natural and devastating disaster. Mitigating or addressing this disaster should be a prior to both general public, governmental and non-governmental organisations as it ripples through many sectors of economy. The importance of adopting a Drought policy cannot be over emphasised. According to IRIN (2012) and Garrotte et al (2007) mentioned a Drought Policy would not only involve putting policies in place but could also serve as a safety net for protection to the affected victims. Adopting a Drought Policy by states at international, national and local level can mitigate the effects of this hazard. It is important for countries and states to consider and take such step towards implementing the policy. 


\section{References}

Alexandra, D. (2002). Principles of emergency planning and management, Terra Publishing UK and Oxford University Press, USA.

Davies, E. G. R. and Simonovic, S. P. (2011). Global water resources modeling with an integrated model of the social-economic-environmental system, Advances in Water Resources, 34: 684-700.

El Kharraz, J., El-Sadek, A., Ghaffour, N. and Mino, E. (2012). Water scarcity and drought in WANA countries, Procedia Engineering, 33: 14 - 29.

Garrote,L., Martin-carrasco, F., Flores-Montoya, F. and Iglesias, A. (2007). Linking Drought Indicators to Policy Actions in the Tagus Basin Drought Management Plan, Water Resour Manage, 21: 873-882

Georgia Drought Management Plan (2003). Environmental Protection Division DNR http://www.georgiaplanning.com/watertoolkit/Documents/WaterConservationDroughtManagement/ DroughtMgtPlanFinal03.pdf accessed on 28/6/2012.

Gosling, S. N., Nigel, W. A. and Jason A. L. (2010). The implications of climate policy for avoided impacts on water scarcity, Procedia Environmental Science, 64: 112-121.

Hamdy, A., Ragab, R. and Elisa., S. (2003). Coping with water scarcity: water saving and productivity, Irrigation and Drainage, 52: 3-20.

IRIN Global Africa (2012). Humanitarian news and analysis a service of the UN Office for the Coordination of Humanitarian Affairs. On http://www. irinnews.org/Report/92676/GLOBAL-Nationaldrought-policies-wante.accessed on 6/7/2012

Kampragou, E., Apostolaki, S., Manoli, E., Froebrich, J. and Assimacopoulos, D. (2011). Towards the harmonization of water-related policies for managing drought risks across the EU, Environmental Science and Policy, 14: 815-824.

Leon, W. (2012). As rivers run dry right across the country, the water companies tell us we mustn't spend more than Four minutes in the shower, Mail Online. http://www.dailymail.co.uk/news /article-2103809/UK-drought-2012-Water-companies-say-mustnt-spend-Four-minutes-shower.html \#ixzz251V37Env accessed on 26/6/2012.

Molden, D. (2007). Water for food, Water for life: A Comprehensive Assessment of Water Management in Agriculture, Earthscan/IWMI .

NASA (2009). The water cycle http://science.nasa.gov/earth-science/oceanography/ocean-earthsystem/ocean-water-cycle/accessed on 18/6/2012.

Nelson, R., Howden, M. and Smith, M. S. (2008). Using adaptive governance to rethink the way science supports Australian drought policy, Environmental Science and Policy, 11: 588 - 601.

Nyemba, A., Manzungu, E., Masango, S. and Simon, M. (2010). The impact of water scarcity on environmental health in selected residential areas in Bulawayo City, Zimbabwe, Physics and Chemistry of the Earth, 35: 823-827.

Pru"ss, A., Day, K., Fewtrell, L. and Bartram, J. (2002). Estimating the global burden of disease from water, sanitation and hygiene at a global level, Environ. Health Perspect, 110: 537-542.

Rijsberman. F. R. (2006). Water scarcity: Fact or fiction?, Agricultural Water Management, 80: 5-22.

SABMiller and WWF. (2009). Water futures working together for a secure water future

Sivakumar, M. V. K. and Wilhte, D. A. (2002). Drought preparedness and drought management. ICIDCIID international conference on drought mitigation and prevention of land desertification, key note presentation, Bled, Slovenia, 21-15 April.

Sivakumar, M. V. K., Motha, R. P., Wilhite, D. A. and Qu, J. J. (2011). Towards a Compendium on National Drought Policy, Proceedings of an Expert Meeting, Washington DC, USA.

Stefanski, R. (2011). Drought management and policies: World Meteorological Organisation (WMO) drought initiatives

White, D. H and Karssies, L. (2009). Australia's National Drought Policy, Water International, 24(1): 2-9.

Wilhite, D.A. (2000). Drought: A Global Assessment, Routledge, 1-2: 129-448.

Wilhite, D.A., 2000b. Drought as a natural hazard: concepts and definitions, Routledge, 1: 1-18.

U.S Geological survey (2009) water cycle http://www.usgs.gov/ accessed on 20/6/2012.

UN (2007). Coping with water scarcity challenge of the twenty first century, World water day. 
